\title{
Culture of equine fibroblast-like synoviocytes on synthetic tissue scaffolds towards meniscal tissue engineering: a preliminary cell- seeding study
}

Introduction: Tissue Engineering is a new methodology for addressing meniscal injury or loss. Synovium may be an ideal source of cells for in vitro meniscal fibrocartilage formation, however, favorable in vitro culture conditions for synovium must be established in order to achieve this goal. The objective of this study was to determine cellularity, cell distribution, and extracellular matrix (ECM) formation of equine fibroblast-like synoviocytes (FLS) cultured on synthetic scaffolds, for potential application in synovium-based meniscal tissue engineering. Scaffolds included open-cell poly-L-lactic acid (OPLA) sponges and polyglycolic acid (PGA) scaffolds cultured in static and dynamic culture conditions, and PGA scaffolds coated in poly-L-lactic (PLLA) in dynamic culture conditions. Materials and Methods: Equine FLS were seeded on OPLA and PGA scaffolds, and cultured in a static environment or in a rotating bioreactor for 12 days. Equine FLS were also seeded on PGA scaffolds coated in $2 \%$ or $4 \%$ PLLA and cultured in a rotating bioreactor for 14 and 21 days. Three scaffolds from each group were fixed, sectioned and stained with Masson's Trichrome, Safranin-O, and Hematoxylin and Eosin, and cell numbers and distribution were analyzed using computer image analysis. Three PGA and OPLA scaffolds from each culture condition were also analyzed for extracellular matrix (ECM) production via dimethylmethylene blue (sulfated glycosaminoglycan) assay and hydroxyproline (collagen) assay. PLLA coated PGA scaffolds were analyzed using double stranded DNA quantification as areflection of cellularity and confocal laser microscopy in a fluorescent cell viability assay. Results: The highest cellularity occurred in PGA constructs cultured in a rotating bioreactor, which also had a mean sulfated glycosaminoglycan content of 22.3ug per scaffold. PGA constructs cultured in static conditions had the lowest cellularity. Cells had difficulty adhering to OPLA and the PLLA coating of PGA scaffolds; cellularity was inversely proportional to the concentration of PLLA used. PLLA coating did not prevent dissolution of the PGA scaffolds. All cell scaffold types and culture conditions produced non-uniform cellular distribution. Discussion/ Conclusion: FLS-seeding of PGA scaffolds cultured in a rotating bioreactor resulted in the most optimal cell and matrix characteristics seen in this study. Cells grew only in the pores of the OPLA sponge, and could not adhere to the PLLA coating of PGA scaffold, due to the hydrophobic property of PLA. While PGA culture in a bioreactor produced measureable GAG, no culture technique produced visible collagen. For this reason, and due to the dissolution of PGA scaffolds, the culture conditions and scaffolds described here are not recommended for inducing fibrochondrogenesis in equine FLS for meniscal tissue engineering. 
1 Culture of equine fibroblast-like synoviocytes on synthetic tissue scaffolds towards meniscal

2 tissue engineering: a preliminary cell- seeding study

3 1) Jennifer J. Warnock, Comparative Orthopaedic Laboratory, University of Missouri, Columbia, MO; Dr. Warnock's current address is College of Veterinary Medicine, Oregon State University, Corvallis OR

2) Derek B. Fox, Comparative Orthopaedic Laboratory, University of Missouri, Columbia, $\mathrm{MO}$;

3) Aaron M. Stoker, Comparative Orthopaedic Laboratory, University of Missouri, Columbia, MO

4) Mark Beatty, VA Nebraska-Western Iowa Health Care System and University of Nebraska Medical Center College of Dentistry, Lincoln, NE

5) Mary Cockrell, Comparative Orthopaedic Laboratory, University of Missouri, Columbia, $\mathrm{MO}$

6) John C. Janicek, Comparative Orthopaedic Laboratory, University of Missouri, Columbia, $\mathrm{MO}$

7) James L. Cook, Comparative Orthopaedic Laboratory, University of Missouri, Columbia, $\mathrm{MO}$

18 This study was funded by the Comparative Orthopaedic Laboratory, University of Missouri,

19 Columbia, MO 65211

CORRESPONDING AUTHOR:

Jennifer J. Warnock,

Dr. Warnock's current address is:

Magruder Hall, College of Veterinary Medicine

25 Oregon State University, Corvallis OR 97331

26 541-737-4812

27 jennifer.warnock@,oregonstate.edu

28 Dr. Janicek's current address is

29 Brazos Valley Equine Hospital

30 Navasota, TX 77868 


\section{Introduction:}

The knee menisci are semilunar-shaped fibrocartilages with extracellular matrix (ECM)

33 composed primarily of types I and II collagen, glycosaminoglycans (GAGs), and water (Fithian

34 et al. 1990). It is now well established that intact menisci are crucial for the maintenance of

35 normal joint function, however these critical structures are frequently injured in humans and

animals. Meniscal tears are the most common knee injury in people, and arthroscopic

meniscectomy represents the most common human orthopedic surgery performed annually

(Burks et al. 1997). Meniscal injuries are also a significant cause of lameness and decreased

performance in horses (Peroni \& Stick 2002; Walmsley 1995; Walmsley et al. 2003); equines

affected by naturally occurring meniscal tears may also be a viable model for the study of human

41 meniscal injury.

As the axial, avascular portion of the meniscus has a limited ability to heal spontaneously,

43 (Arnoczky \& Warren 1983; Kobayashi et al. 2004), the majority of meniscal injuries are treated

44 with partial menisectomy. However, this also results in eventual articular cartilage damage of the

45 tibia and femoral condyles, and progression of debilitating osteoarthritis (Arnoczky \& Warren

46 1983; Cox et al. 1975). Thus tissue engineering new meniscal fibrocartilage is being investigated

47 as a treatment for avascular meniscal injuries.

Synovium may be an ideal cell source for meniscal tissue engineering. Synovium plays an

49 important role in attempted vascular zone healing and regeneration (Cisa et al. 1995; Kobuna et

al. 1995; Ochi et al. 1996; Shirakura et al. 1997). Synovium has the ability to form

51 fibrocartilaginous-like tissue in vivo in response to meniscectomy (Cox et al. 1975). In addition,

52 synoviocytes have been reported to be an important element in cellular repopulation of meniscal

53 allografts (Arnoczky \& Warren 1983; Rodeo et al. 2000). Synovial tissue progenitor cells, grossly

54 indistinguishable in culture from type B or fibroblast-like synoviocytes (FLS), can undergo

55 chondrogenesis in vitro (De Bari et al. 2001; Nishimura et al. 1999). Taken together, these data 
56 indicate that synovium may be able to serve as a source for functional fibrocartilage in

57 engineering meniscal tissue, provided the chondrogenic potential of synoviocytes can be

58 optimized.

59 Tissue engineering scaffolds must provide substrate and stability for cellular retention,

60 intercellular communication, and cellular growth to allow seeded cells to proliferate extracellular

61 matrix (ECM). As the scaffolds naturally degrade, the cellular ECM must be able to take on the

62 biomechanical function and form previously designated by the scaffolds to maintain construct

63 integrity. Thus a scaffold must be hydrophilic enough to allow cell adhesion but have a long

64 enough half- life to not prematurely dissolve, which would prevent ECM proliferation and cell

65 death. PGA (poly -glycolic acid) and PLA (poly-L- lactic acid) are biodegradable,

66 biocompatible, poly-esters, that are attractive for tissue engineering because they are readily

67 available, can be easily processed into a variety of structures, and are approved by the Food and

68 Drug Administration for a number of biomedical applications (Lavik et al. 2002). PGA has been

69 successfully used as a scaffold for meniscal fibrochondrocytes in vivo (Kang et al. 2006) and

70 cultured in vitro (Aufderheide \& Athanasiou 2005) to form meniscal-like tissue. Another scaffold

71 type, PLLA, (poly-L lactic acid) has been successfully used for in vitro tissue engineering of

72 leporine meniscal fibrochondrocytes (Esposito et al. 2013; Gunja \& Athanasiou 2010),

73 chondrocytes (Sherwood et al. 2002), and human fibroblasts (Hee et al. 2006). PGA -PLLA

74 combinations have also been successfully used for in vitro meniscal culture (Ionescu \& Mauck

75 2013). In addition, chondrocytes cultured on PGA-PLLA mixtures versus collagen sheets contain

76 more collagen type II and have stronger mechanical properties (Beatty et al. 2002) than single

77 polymer scaffolds. Further investigation of combination use of PLLA combined with PGA for in

78 vitro synoviocyte culture is warranted.

79 Cartilage and fibrocartilage engineering with biodegradable scaffolds is most successful if

80 uniform cell distribution is achieved (Davisson et al. 1999; Pazzano et al. 2000; Smith et al. 
81 1995), which is optimized through the use of rotating bioreactors(Aufderheide \& Athanasiou

82 2005; Kim et al. 1998; Pazzano et al. 2000). In addition, rotating bioreactors provide mechanical

83 stimulation of cultured cells. This has a positive effects on cell differentiation, cell viability,

84 extracellular matrix production, and compressive biomechanical properties, through

85 mechanotransductive effects (Davisson et al. 1999; Imler et al. 2004; Pazzano et al. 2000; Smith

86 et al. 1995). Thus scaffold culture in a rotating bioreactor may represent a useful technique for

87 synoviocyte- based engineering of functional meniscal tissue.

Based on this prior research, we believe that both PGA and PLLA would be viable synthetic scaffolds for the in vitro culture of FLS for application in meniscal fibrocartilage tissue engineering. Thus, the first objective of this study was to 1) determine cell distribution and ECM formation of equine FLS seeded and cultured dynamically in a rotating bioreactor versus static seeding and culture, on two synthetic scaffold types, PGA and open- cell PLLA (OPLA). The second objective was to compare cell viability, distribution, and ECM formation of FLS cultured on $2 \%$ vs $4 \%$ PLLA coated PGA scaffolds, cultured for 14 or 21 days. Our hypothesis was that we would see no difference in equine FLS content, FLS distribution, and ECM formation between scaffold type, biomechanical culture environment, and culture duration.

\section{Materials and Methods:}

\section{Experiment 1:}

Tissue Collection and Monolayer Cell Culture-- Six $8.0 \mathrm{~mm}$ x $8.0 \mathrm{~mm}$ biopsies of synovial intima and subintima were obtained from both stifles of an adult American Quarter

101 Horse, euthanatized according the American Veterinary Medical Association's guidelines for 102 humane euthanasia, for reasons unrelated to the study. The horse was determined to be free of

103 orthopedic disease based on pre-mortem physical examination and post mortem gross

104 examination of the joint. Tissue was placed in Dulbeccos' Modified Eagle's Media (DMEM) with $10510 \%$ fetal bovine serum, 0.008\% Hepe's buffer, $0.008 \%$ non-essential amino acids, $0.002 \%$ 
106 penicillin 100I.U./mL streptomycin 100ug/mL, amphoterocin B 25ug/mL, 0.002\% L-ascorbate,

107 and $0.01 \%$ L-glutamine in preparation for monolayer culture.

108 Synovium was sectioned into $2.0 \mathrm{~mm} \times 2.0 \mathrm{~mm}$ pieces using a \#10 Bard Parker blade

109 under sterile conditions. The tissue fragments were combined with sterile Type 1A clostridial

110 collagenase solution (Type 1A Clostridial Collagenase, Sigma, St. Louis, MO) at a concentration

111 of $7.5 \mathrm{mg} / \mathrm{mL}$ of RPMI 1640 solution. The mixture was agitated at $37^{\circ} \mathrm{C}, 5 \% \mathrm{CO} 2,95 \%$ humidity

112 for six hours. Cells were recovered through centrifugation, the supernatant decanted and the

113 cellular pellet re-suspended in 5mL of supplemented DMEM. The cell solution was transferred to

114 a $25 \mathrm{~cm}^{2}$ tissue culture flask containing $5 \mathrm{~mL}$ of supplemented DMEM. The flasks were incubated

115 at $37^{\circ} \mathrm{C}, 5 \% \mathrm{CO} 2,95 \%$ humidity, with sterile medium change performed every 3 days. Synovial

116 cells were monitored for growth using an inverted microscope until observance of 95\% cellular

117 confluence per tissue culture flask. At second passage cells were transferred to $75 \mathrm{~cm}^{2}$ tissue

118 culture flasks containing $11 \mathrm{~mL}$ of media. At $95 \%$ confluence the cells were subcultured until the

119 4th cell passage had been reached. At $4^{\text {th }}$ passage cells were removed from flasks, counted using

120 the Trypan Blue exclusion assay (Strober 2001), and transferred to scaffold culture as described

121 below.

122 Scaffolds-A non- woven polyglycolic acid (PGA, Tissue Scaffold, Synthecon, Houston,

123 TX) felt, $3 \mathrm{~mm}$ thick, with $10 \mu \mathrm{m}$ diameter fibers was utilized for this study. The open-cell poly-

124 lactic acid (OPLA sponge, BD Biosciences, Bedford, MA) utilized were 5.0mmx 3.0mm, non

125 compressible, cylindrical sponges. The average OPLA sponge pore size was $100-200 \mu \mathrm{m}$ with a

126 hydration capacity of $30 \mu \mathrm{l} /$ scaffold. PGA and OPLA scaffolds were sterilized in ethylene oxide.

127 Following sterilization, the PGA felt was cut using a sterile Baker's biopsy punch to create into

$1285.0 \mathrm{~mm} \times 3.0 \mathrm{~mm}$ discs prior to cell culture to match the dimensions of the OPLA scaffolds.

129 Dynamic Culture-- Twelve PGA scaffolds (PGA-D group) and 12 OPLA sponges (OPLA-

130 D group) were placed in separate $110 \mathrm{~mL}$ vessel flasks of a rotating bioreactor system (Rotating 
131 Bioreactor System, Synthecon, Houston, TX (Fig. 1) containing 110mL of supplemented DMEM.

132 The scaffolds were presoaked for 24 hours in the bioreactor at $37^{\circ} \mathrm{C}, 5 \% \mathrm{CO} 2,95 \%$ humidity,

133 prior to cell introduction. Fourth passage FLS were removed from the tissue culture flasks

134 enzymatically (Accutase Innovative Cell Technologies, San Diego, CA) and counted. Cells were

135 added to the $110 \mathrm{~mL}$ bioreactor flasks at a concentration of 1 million cells/ scaffold via a $60 \mathrm{cc}$

136 syringe, slowly injected over several minutes. For the duration of the study the bioreactor vessels

137 were rotated at $51.1 \mathrm{rpm}$ to allow the scaffolds to free-float and rotate within the culture medium,

138 without contacting the inner bioreactor surfaces. Cultures were maintained at $37^{\circ} \mathrm{C}, 5 \% \mathrm{CO} 2$,

$13995 \%$ humidity. Fifty percent of the cell culture medium volume was changed using sterile

140 technique every 3 days. Cell counts were performed on discarded media for the first two media

141 changes.

142 Static Culture-- Twelve PGA scaffolds (PGA-S group) and 12 OPLA sponges (OPLA-S

143 group) were placed individually in non- treated 24 well tissue culture plates, each well containing

$1442 \mathrm{~mL}$ of supplemented DMEM (Fig. 2). The scaffolds were presoaked for 24 hours at $37^{\circ} \mathrm{C}, 5 \%$

$145 \mathrm{CO} 2,95 \%$ humidity, prior to cell introduction. Then FLS were transferred from monolayer

146 culture as described above, and slowly over 3 minutes, pipetted on top of the scaffolds in

147 solution, at 1 million cells per scaffold in each well. The plates were maintained at $37^{\circ} \mathrm{C}, 5 \%$

$148 \mathrm{CO} 2,95 \%$ humidity, with 50\% cell culture medium changed every 3 days. Cell counts were

149 performed on discarded media for the first 2 media changes.

150 Histologic Analysis-- All scaffolds were harvested on the $12^{\text {th }}$ day of culture. Six scaffolds

151 from each group (PGA-S, PGA-D, OPLA-S, OPLA-D) were fixed in 10\% buffered formalin,

152 embedded in paraffin, sectioned, and stained with Masson's Trichrome, Safranin -O, and

153 Hematoxylin and Eosin. Histologic specimens were examined at 10x magnification (Zeiss

154 Microscope, Carl Zeiss, Thornwood, NY). Images of each section, (three from the scaffold

155 periphery and three from the scaffold center) at 2 o'clock, 6o'clock and 10o'clock positions (Fig. 
156

157

158

159

160

161

162

163

164

165

166

167

168

169

170

171

172

173

174

175

176

177

178

179

3) were digitally captured by a digital camera (Olympus DP-70 Olympus, Melville, NY) and saved as tagged- image file format images. Digital image analysis was performed as previously validated (Amin et al. 2000; Benzinou et al. 2005; Girman et al. 2003; Goedkoop et al. 2005) whereby cellular density was assessed using a thresholding algorithm (Loukas et al. 2003) using computer image analysis (Fovea 3.0, Reindeer Graphics, Asheville, NC). This algorithm allows quantification of cellular nuclei based on their histogram values. All cell counts were additionally validated by hand counts. Safranin-O staining, indicating presence of GAG, and Masson's Trichrome staining, indicating presence of collagen, were subjectively evaluated and recorded.

Biochemical ECM Analysis-- Three cultured scaffolds from each group were analyzed for glycosaminoglycan (GAG) and collagen production. Wet weight of each scaffold was obtained. GAG content of the scaffold was performed using the Dimethyl-methylene Blue Sulfated Glycosaminoglycan assay (Farndale et al. 1986). Collagen content of the cultured scaffolds was assessed using the hydroxyproline assay, as described by Reddy et al.(Reddy \& Enwemeka 1996).

Statistical Methods_-Data were tested for normality using a Shapiro-Wilk test.

Data were then analyzed using a one way analysis of variance followed by a Tukey's test, to compare the effect of scaffold type and seeding technique on cell counts and ECM quantity. To determine significance between periphery and central cell counts within each scaffold, a paired, 2-tailed student's t-test was performed. For all tests significance was set at $\mathrm{P}<0.05$. All statistical analyses were performed using a statistical software program, (GraphPad Prism Version 6, San Diego, CA). . 
181 and 4\% PLLA solution each was applied to a $3.0 \mathrm{~mm}$ thick sheet of the same, above- described,

182 non- woven PGA felt, using an eye-dropper. Following PLLA treatment, the treated felt was

183 placed in a vacuum dessicator overnight and then sterilized in ethylene oxide. Following

184 sterilization, the $2 \%$ and $4 \%$ PLLA modified PGA felts were cut into fourteen $5 \mathrm{mmx} 7 \mathrm{mmx} 3 \mathrm{~mm}$

185 square scaffolds using sterile scissors and a \#10 bard parker blade (Fig 4).

harvested from the stifles of two mixed breed, adult horses euthanatized according the American

Veterinary Medical Association's guidelines for humane euthanasia, for reasons unrelated to the

study. These horses were also determined to be free of orthopedic disease based on pre-mortem

physical examination and post mortem gross examination of the joint. The tissue was

191 transported, minced and digested as described above. Cells were recovered through

centrifugation, the supernatant decanted and the cellular pellet re-suspended in $5 \mathrm{~mL}$ of

supplemented DMEM. The cell solution was transferred to a $25 \mathrm{~mL}$ tissue culture flask containing

$5 \mathrm{~mL}$ of supplemented DMEM. Cells were grown in monolayer culture, under the conditions

described above, until the $4^{\text {th }}$ cell passage had been reached.

Dynamic Culture-- Fourteen 2\% PLLA coated PGA scaffolds and fourteen 4\% PLLA the bioreactor at $37^{\circ} \mathrm{C}, 5 \% \mathrm{CO} 2,95 \%$ humidity, prior to cell introduction. After this time it was noted that the scaffolds were floating at the apex of the flasks. Using sterile surgical technique,

201 scaffolds were sterily removed from the flasks, pierced centrally, and strung on loops of 3-0

202 nylon surgical suture with knots placed adjacent to the scaffolds to prevent bunching on the line.

203 Seven scaffolds were placed per suture. The strings of scaffolds were then placed back in to the 
204 bioreactors and presoaked for another 12 hours, at which time complete hydration and

205 submersion were achieved (Fig. 5).

206

Scaffolds were then dynamically seeded. Synovial membrane cells were removed from

207 the tissue culture flasks using as described above and counted using the Trypan Blue exclusion

208 assay (Strober 2001). Cells were added to the bioreactor flasks at a concentration of 475,000

209 cells per $\mathrm{mL}$.

210 For the duration of culture, the bioreactor was maintained at $37^{\circ} \mathrm{C}, 5 \% \mathrm{CO} 2,95 \%$

211 humidity at $51.1 \mathrm{rpm}$. Fifty percent of the cell culture medium volume was changed using sterile

212 technique every 3 days. Seven scaffolds were harvested on day 10 of culture, and 7 scaffolds

213 were harvested on day 21 of culture.

214 Determination of Cell Viability-- Cell viability was determined with the use of ethidium

215 homodimer-1 (4ul/ml PBS) and Calcein AM (Acetoxymethylester) $(0.4 \mathrm{ul} / \mathrm{ml} \mathrm{PBS})$ fluorescent

216 stains (Invitrogen, Carlsbad CA) and the use of Confocal Laser Microscopy. The Confocal Laser

217 Microscope consists of the BioRad Radiance 2000 confocal system coupled to an inverted

218 microscope (Olympus IX70 Olympus, Melville, NY) equipped with Krypton-Argon and red

219 diode laser. Approximately $1.0 \mathrm{~mm}$ sections were made from the halved scaffold using a rotary

220 paper cutter. A section from each scaffold's cut center and a section from each scaffold's

221 periphery was examined. Sections were incubated with the staining agents for 30 minutes at room

222 temperature, placed on a glass microscope slide, moistened with several drops of PBS, and

223 stained using the fluorescent double labeling technique. The sections were examined under 10x

224 magnification. Images were taken of each specimen as described above, (three from the section

225 periphery and three from the section center) at the 2 o'clock, 6o'clock and 10o'clock positions.

226 Images were digitally captured as described above. Live and dead cell counts were determined by

227 hand counts. 
229 obtained. Samples were incubated in 1.0ml Papain Solution (2mM Dithiothreitol and 300ug/ml

230 Papain) at $60^{\circ} \mathrm{C}$ in a water bath for 12 hours. A double stranded DNA quantification assay

231 (Quant-iT PicoGreen ${ }^{\mathrm{TM}}$ Invitrogen, Carlsbad, CA) was performed. Double stranded DNA

232 extracted from bovine thymus was mixed with TE buffer (Invitrogen, Carlsbad, CA) to create 233 standard DNA concentrations of 1,000, 100, 10, and $1 \mathrm{ng} / \mathrm{mL}$. The standards and 100uL of each

234 papain digested sample (used in the above GAG and hydroxyproline assays) were added to a 235 black 96 well plate. $100 \mathrm{uL}$ of $2 \mathrm{ug} / \mathrm{mL}$ of Pico Green reagent was added to each well and the 236 plate was incubated for 5 minutes. Sample fluorescence was read at 485nm excitation/528nm

237 emission by a spectrophotometric plate reader (Synergy HT - KC-4, BioTek, Winooski, VT).

238 Absorbances were converted to $\mathrm{ng} / \mathrm{mL}$ concentrations and total double stranded DNA yield in ng 239 using FT4 software (BioTek, Winooski, VT).

240 Statistical Methods - Data were tested for normality using a Shapiro-Wilk test. Scaffold

241 weights were compared using a 2-tailed paired t-test. Scaffold dsDNA content was analyzed

242 using a repeated- measures analysis of variance with a Geisser-Greenhouse correction.

243 Significance was set at $\mathrm{p}<0.05$. All statistical analyses were performed using a statistical

244 software program, (GraphPad Prism Version 6, San Diego, CA).

\section{Results}

246 Experiment 1:

247 As determined by the Trypan Blue exclusion assay, viability of cells at the time of transfer

248 from monolayer culture to static or dynamic seeding was 98.6\%. No live cells were detected in

249 any of the media changes for either static or dynamically cultured scaffolds, indicating that viable

250 cells rapidly adhered to the scaffolds. 
At the time of harvest upon gross examination, the fibers of the PGA scaffolds and the sponge

252

253

254

255

256

257

258

259

260

261

262

263

264

265

266

267

268

269

270

271 surface of the OPLA scaffolds were still visible. PGA scaffolds subjectively appeared more translucent.

Despite equal cell seeding concentrations, the effect of dynamic bioreactor culture on cell content of PGA scaffolds (PGA-D versus PGA-S) was to increase scaffold cellularity $(\mathrm{P}<0.001)$. This was also found in OPLA-D versus OPLA-S scaffolds $(\mathrm{P}=0.028)$. The effect of scaffold type also significantly increased scaffold cellularity of PGA-D versus OPLA-D ( $\mathrm{P}=0.017)$, while OPLA-S had great cellularity than PGA-S $(\mathrm{P}=0.0217$; Table 1).

All groups, with the exception of OPLA-S, showed increased cellular distribution to the periphery of the scaffolds (Table 2). Due to the shape of the OPLA-S on histological sectioning, there was overlap of central and peripheral fields of view, precluding accurately localized cell counts; peripheral cell count was $307 \pm 52$ and central cell count was $287 \pm 80(\mathrm{P}<0.464)$. Cells grew in whorls, strands, and sheets on the PGA scaffolds, while cells grew in clumps on the surface pores of the OPLA sponges (Fig. 6).

Staining for collagen and gycosaminoglycan using Masson’s Trichrome and Safranin-O, respectively, was negative for extracellular matrix production in all sections of all scaffold types and culture conditions evaluated.

In the PGA-D group, the dimethylmethylene blue assay detected a mean of $22.29 \mu \mathrm{g}$ of GAG

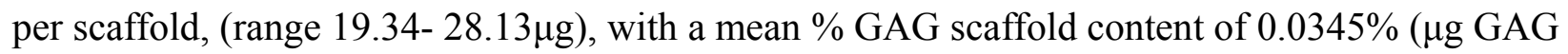
per $\mu \mathrm{g}$ scaffold wet weight). No GAG was detected in OPLA constructs or PGA-S constructs. The hydroxyproline assay did not detect collagen production in any group.

\section{Experiment 2:}

273 Post PLLA modification, mean scaffold dry weights before soaking and seeding were $2741.01 \mathrm{mg}$ for $2 \%$ PLLA coating and $1.52 \mathrm{mg}$ for $4 \%$ PLLA coating $(\mathrm{P}<0.001)$. Scaffold dry weights 
275 decreased over time. Mean lyophilized weight on day 10 for $2 \%$ PLLA coating was $0.533 \mathrm{mg}$, 276 which decreased to $0.257 \mathrm{mg}$ on day $21(\mathrm{P}=0.02)$. Mean lyophilized weight on day 10 for $4 \%$

277 PLLA coating was $0.481 \mathrm{mg}$, which decreased to $0.381 \mathrm{mg}$ on day $21(\mathrm{P}=0.043)$.

278 Scaffold cellularity as measured by dsDNA content increased over time: for the $2 \%$

279 group, day 10 cellularity was $102.6 \mathrm{ng}$ dsDNA/mg dry weight, and on day 21 it was 281.79

$280(\mathrm{P}=0.021)$. On day 10 for the 4\% group, dsDNA content was $111.01 \mathrm{ng} \mathrm{dsDNA} / \mathrm{mg}$ dry weight

281 and on day 21 it was $140.2 \mathrm{ng}$ dsDNA/mg dry weight $(\mathrm{P}=0.032$; Fig. 7).

282 PLLA coating also affected scaffold dsDNA content. Scaffolds with the $2 \%$ PLLA coating

283 had greater dsDNA content than the 4\% PLLA coating on day $21(\mathrm{P}=0.003)$, but not on day 10 $284(\mathrm{P}=0.602 ;$ Fig 7$)$.

As visible under confocal microscopy, cells only adhered to the surface of exposed PGA

286 fibers and had poor to no penetration to the scaffold centers in all PLLA coated scaffolds. Viable 287 cell numbers were estimated only because of the marked cellular clumping; all scaffolds showed 288 mixtures of viable and non- viable cells localized in clumps on the scaffold outer margins (Figs 8289 11). Histologic examination of $\mathrm{H}+\mathrm{E}$ stained constructs revealed minimal cellular adhesion to the 290 PLLA, in all groups at all times, with cells growing primarily on the exposed PGA scaffold, in 291 tightly packed clumps, or adhering to exposed fibers of PGA. No extracellular matrix was 292 observed in any scaffolds on histologic analysis, which also reflected the uneven cellularity (Fig 293 12).

\section{Discussion:}

295 The current study analyzed the effect of scaffold type, biomechanical stimuli, and culture 296 duration on FLS seeding and production of specific meniscal ECM constituents. We found that

297 FLS-seeded PGA constructs cultured in a rotating bioreactor had the highest cellularity, with a 298 mean sulfated glycosaminoglycan content of $22.3 \mu \mathrm{g}$ per scaffold. PGA constructs cultured in 
static conditions had the lowest cellularity. For PLLA coated PGA, increasing concentration of

PLLA decreased scaffold cellularity, while increased culture time increased scaffold cellularity, as

301 determined by the dsDNA assay. A non-uniform cellular distribution was observed for all scaffold

302 types and culture conditions.

303 Bioreactor culture provides a number of benefits over static culture, which would account for

304 the higher cellularity of PGA-D and OPLA-D versus PGA-S and OPLA-S scaffolds. The

305 rotating wall bioreactor used in this study provided a dynamic, laminar fluid shear, which

306 perfuses scaffold cultured cells (Bilodeau \& Mantovani 2006), and thereby encourages cell

307 survival and proliferation by providing efficient transport of nutrients, gases, catabolites, and

308 metabolites and maintaining physiologic media pH (Gooch et al. 2001; Vunjak-Novakovic et al.

309 1998). Mixing of culture media also promotes cell seeding by creating matched relative

310 velocities of cells and scaffolds, particularly on non-woven PGA scaffolds (Vunjak-Novakovic et

311 al. 1998). In addition, the rotating wall bioreactor limits cellular stress by reducing strong shear

312 forces and cellular impact on the walls of the bioreactor (Bilodeau \& Mantovani 2006).

313 However, in our study, scaffold characteristics such as scaffold density and hydrophilicity may

314 have negated the advantages of bioreactor culture, as seen with OPLA or PLLA coated scaffolds,

315 which had fewer cells and markedly uneven cell distribution, respectively.

316 A higher cell count was found on PGA-D versus OPLA-D, indicating either better adherence

317 or cell proliferation on PGA. Non-woven PGA scaffolds favor cellular capture and retention

318 because of their polar surface properties and high surface area for cellular adhesion (Day et al.

319 2004; Moran et al. 2003). Cellularity of PGA-D was further increased by the open weave and

320 low density $(45-77 \mathrm{mg} / \mathrm{cc})$ of PGA scaffolds supports cellular proliferation through superior flow-

321 through of culture media and nutrient delivery (Vunjak-Novakovic et al. 1998). This is in contrast

322 to the highly dense $(871 \mathrm{mg} / \mathrm{cc})$ OPLA sponges with non-communicating pores, which could

323 inhibit nutrient and gas transfer to seeded cells (Pazzano et al. 2004; Pazzano et al. 2000; Wu et 
324 al. 1999). For PLLA covered PGA scaffolds, cells were located primarily on exposed PGA fibers,

325 and scaffold cellularity was inversely proportional to the concentration of PLLA. Although PLLA

326 is widely used in tissue-engineering applications because of its slower degradation

327 characteristics, strength, and mechanical properties, its hydrophobic, inert nature can affect cell-

328 matrix interactions and decrease cellular adhesion (Moran et al. 2003). While the PLLA coating

329 of PGA scaffolds was intended to protect from premature scaffold dissolution, we observed that

330 with longer duration of culture, scaffolds appeared to be more fragile to disruption with forceps

331 manipulation, particularly on the outer edges as well as around the centrally placed suture. In

332 agreement with this observation, all scaffold dry weights dropped over time, indicating scaffold

333 dissolution. Thus PLLA did not prevent PGA hydrolysis and decreased scaffold integrity. PLLA

334 coating also provided a hydrophobic barrier to centralized cell seeding and ingrowth. Thus, for

335 the future study of scaffold seeded equine FLS, use of PLLA type scaffolds is not recommended.

336 Cell distribution across all scaffolds was uneven, in contrast to previous reports on bioreactor

337 chondrocyte culture (Mahmoudifar et al. 2005; Pazzano et al. 2004). Lower central cell density

338 in our scaffolds may have indicated poor axial cell penetration and in-growth. Alternatively,

339 higher peripheral cellularity could reflect increased peripheral cell division caused by increased

340 exposure to media nutrients, gas exchange, and mechanotransductive effects (Mahmoudifar et

341 al. 2002). Additionally the OPLA scaffolds had clumped cell distribution in the outermost pores.

342 The OPLA sponge porosity may not allow uniform cell distribution; the $100-200 \mu \mathrm{m}$ pores do not

343 consistently communicate with each other. While OPLA-S did not have different peripheral and

344 central cell counts, this was due to an artifact of the sponge shape and precluded distinction of

345 peripheral cells from central cells. To increase central scaffold cell content, flow-through

346 bioreactors (Bilodeau \& Mantovani 2006) may have greater cell seeding efficiencies than rotary

347 bioreactors. Alternatively, cells may be seeded at the time of scaffold formation, such as during

348 hydrogel synthesis, to insure central scaffold cellularity (Narita et al. 2009). 
The culture conditions utilized in the present study resulted in minimal to no ECM formation,

350 in contrast to other studies. The mean GAG content of the PGA-D scaffold of $0.0345 \%$ (wet

351 weight basis) was lower than the $0.6-0.8 \%$ wet weight in the normal meniscus, and thus

352 represents a sub- optimal response for engineering purposes (AufderHeide \& Athanasiou 2004).

353 Synoviocytes typically produce collagen type I constitutively, (Garner \& al. 2000; Levick 1996),

354 however production and deposition of hydroxyproline was not detected in this study. The most

355 likely reason for this failure of ECM formation was lack of culture with a specific

356 fibrochondrogenic media. For example, culture with recombinant transforming growth factor-

357 beta, insulin-like growth factor -1 and basic fibroblast growth factor have been shown to induce

358 in vitro collagen formation in human synoviocytes (Pei et al. 2008). Treatment of equine FLS

359 with recombinant chondrogenic growth factors, in addition to the scaffold and bioreactor culture

360 conditions used in the present study, resulted in greater type II collagen and aggrecan gene

361 expression (Fox et al. 20010).Reported scaffold seeding concentrations for cartilage tissue

362 engineering include 30,000 fibroblasts/mL (Day et al. 2004); 600,000 chondrocytes/mL (Stading

363 M \& R 1999); 5 million chondrocytes/ mL (Griffon et al. 2005); and 10 million chondrocytes/mL

364 (Hu et al. 2005). Our seeding density of 1 million equine FLS per scaffold may have been too

365 low, as dense cell aggregates are required for meniscal developmental fibrochondrogenesis (Clark

$366 \&$ Ogden 1983) due to the embryonic community effect (Gurdon et al. 1993). In the present study

367 the FLS were exposed to the mild shear forces and hydrostatic pressurization in a rotating

368 bioreactor (Mauck et al. 2002) which may not have been the optimal type of forces required for

369 synovial collagen I formation. A combination of in vitro tensile and compressive

370 forces(AufderHeide \& Athanasiou 2004; Benjamin \& Ralphs 1998) may be required to support

371 formation GAG (Valiyaveettil et al. 2005) and types I and II collagen (Kambic \& McDevitt

372 2005), the major ECM components of fibrocartilage. Cell culture on scaffolds may also result in

373 cellular stress shielding, thereby resulting in suboptimal matrix formation (Huey \& Athanasiou 
374 2011). Synovial macrophages may have contaminated our FLS cultures, thereby also decreasing

375 ECM formation (Pei et al. 2008, Bilgen et al. 2009) and future studies should include negative

376 isolation of macrophages. Additionally, co-culture with meniscal fibrochondrocytes as decribed

377 by Tan and workers (Tan et al. 2010) may have also helped fibrochondrogenic differentiation of

378 equine FLS and will be the focus of future studies. Increased culture time may also be beneficial

379 to ECM formation; other studies show time dependent ECM expression (Griffon et al. 2005;

380 Mueller et al. 1999; Sha'ban et al. 2008). One study of synovial chondrogenesis on PGA scaffolds

381 utilized a longer culture duration of 60 days, with successful ECM formation (Sakimura et al.

382 2006). Despite better cellularity, PGA scaffolds began loosing integrity over the culture period,

383 even when coated with PLLA. Unless rapid ECM formation can be achieved before dissolution

384 occurs, PGA hydrolyzes too quickly ( $\mathrm{t} 1 / 2=16$ days) for the purpose of long term meniscal

385 fibrocartilage synthesis. Treatment with chondrogenic or fibrochondrogenic media may induce

386 production of ECM, thus making the culture systems described here more feasible for meniscal

387 tissue engineering.

388 Conclusion:

389 In conclusion, we reject the null hypothesis; dynamic cell seeding and culture, as well as

390 increased culture duration, increased scaffold cellularity. Scaffold type also affected cellularity;

391 for bioreactor culture, PGA had higher cell counts versus OPLA, while OPLA had higher cell

392 counts versus PGA in static culture. Cells could only grow unevenly in the pores of the OPLA

393 sponge, and cells could not adhere to the PLLA coating of PGA scaffolds. Increasing the

394 concentration of PLLA coating on a PGA scaffold decreased the cellularity of the scaffold, and

395 did not prevent scaffold dissolution. While PGA culture in a bioreactor produced measureable

396 GAG, no culture technique produced visible collagen. For this reason, and due to the dissolution

397 of PGA scaffolds, the exact culture of conditions described here are not recommended for

398 inducing equine fibrochondrogenesis towards meniscal tissue engineering. Further research is 
recommended to enhance extracellular matrix production through additional biomechanical and biological stimulation, including treatment with chondrogenic media, increased culture duration, and increased cell seeding concentrations.

This study was funded by the Comparative Orthopedic Laboratory, University of Missouri. The authors have no conflicts of interest to disclose.

Amin M, Kurosaki M, Watanabe T, Tanaka S, and Hori T. 2000. A comparative study of MIB-1 staining indices of gliomas measured by NIH Image analysis program and conventional manual cell counting method. Neurologic Research 22:495-500.

Arnoczky SP and Warren RF. 1983. The microvasculature of the meniscus and its response to injury. An experimental study in the dog. Am J Sports Med 11:131-141.

AufderHeide AC and Athanasiou KA. 2004. Mechanical stimulation toward tissue engineering of the knee meniscus. Ann Biomed Eng 32:1161-1174.

Aufderheide AC and Athanasiou KA. 2005. Comparison of scaffolds and culture conditions for tissue engineering of the knee meniscus. Tissue Eng 11:1095-1104.

Beatty MW, Ojha AK, Cook JL, Alberts LR, Mahanna GK, Iwasaki LR, and Nickel JC. 2002. Small intestinal submucosa versus salt-extracted polyglycolic acid-poly-Llactic acid: a comparison of neocartilage formed in two scaffold materials. Tissue Eng 8:955-968.

Benjamin M and Ralphs JR. 1998. Fibrocartilage in tendons and ligaments--an adaptation to compressive load. J Anat 193 ( Pt 4):481-494.

Benzinou A, Hojeij Y, and Roudot A. 2005. Digital image analysis of haematopoietic clusters. Computational Methods and Programs in Biomedicine 77:121-127.

Bilgen B, Ren Y, Pei M, Aaron RK, Ciombor DM. 2009. CD14-negative isolation enhances chondrogenesis in synovial fibroblasts. Tissue Engineering. Part A. 15:3261-3270.

Bilodeau K, and Mantovani D. 2006. Bioreactors for Tissue Engineering: Focus on Mechanical Constraints. A Comparative Review. Tissue Eng12:2367-83. 


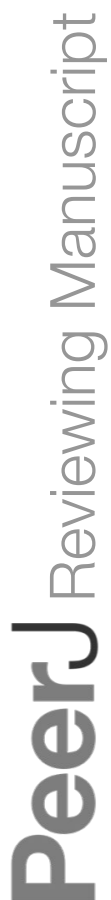

PeerJ reviewing PDF | (v2014:01:1453:2:1:NEW 26 Mar 2014) 
Burks RT, Metcalf MH, and Metcalf RW. 1997. Fifteen-year follow-up of arthroscopic partial meniscectomy. Arthroscopy 13:673-679.

Cisa J, Basora J, Madarnas P, Ghibely A, and Navarro-Quilis A. 1995. Meniscal repair by synovial flap transfer. Healing of the avascular zone in rabbits. Acta Orthop Scand 66:38-40.

Clark CR, and Ogden JA. 1983. Development of the menisci of the human knee joint. Morphological changes and their potential role in childhood meniscal injury. $J$ Bone Joint Surg Am 65:538-547.

Cox JS, Nye CE, Schaefer WW, and Woodstein IJ. 1975. The degenerative effects of partial and total resection of the medial meniscus in dogs' knees. Clin Orthop Relat Res 109:178-183.

Davisson T, Sah R, and Ratcliffe A. 1999. Perfusion increases cell content and matrix synthesis in chondrocyte three- dimensional cultures. Tissue Eng 8:807-816.

Day R, Boccaccini A, and Shurey A. 2004. Assessment of polyglycolic acid mesh and bioactive glass for soft tissue engineering scaffolds. Biomaterials 25:5857-5864.

De Bari C, Dell'Accio F, Tylzanowski P, and Luyten FP. 2001. Multipotent mesenchymal stem cells from adult human synovial membrane. Arthritis Rheum 44:1928-1942.

Esposito AR, Moda M, Cattani SM, de Santana GM, Barbieri JA, Munhoz MM, Cardoso TP, Barbo ML, Russo T, D'Amora U. 2013. PLDLA/PCL-T Scaffold for Meniscus Tissue Engineering. Biores Open Access 2:138-147.

Farndale RW, Buttle DJ, and Barrett AJ. 1986. Improved quantitation and discrimination of sulphated glycosaminoglycans by use of dimethylmethylene blue. Biochim Biophys Acta 883:173-177.

Fithian DC, Kelly MA, and Mow VC. 1990. Material properties and structure-function relationships in the menisci. Clin Orthop Relat Res 252:19-31.

Fox DB, Warnock JJ, Stoker AM, Luther JK, and Cockrell M. 2010. Effects of growth factors on equine synovial fibroblasts seeded on synthetic scaffolds for avascular meniscal tissue engineering. Res Vet Sci 88:326-32.

Garner P. 2000. Molecular basis and clinical use of biochemical markers of bone, and synovium in joint disease. Arthritis and Rheumatism 43:953.

Girman P, Kriz J, Friedmansky J, and Saudek F. 2003. Digital imaging as a possible approach in evaluation of islet yield. Cell Transplantation 12:129-133.

Goedkoop A, Rie Md, Teunissen M. 2005. Digital image analysis for the evaluation of the inflammatory infiltrate in psoriasis. Archives of Dermatological Research 297:51-59.

Gooch KJ, Kwon JH, Blunk T, Langer R, Freed LE, and Vunjak-Novakovic G. 2001. Effects of mixing intensity on tissue-engineered cartilage. Biotechnol Bioeng 72:402407. 
463

464

465

466

467

468

469

470

471

472

473

474

475

476

477

478

479

480

481

482

483

484

485

486

487
Griffon D, Sedighi M, Sendemir-Urkmez A. 2005. Evaluation of vacuum and dynamic cell seeding of polyglycolic acid and chitosan scaffolds for cartilage engineering. American Journal of Veterinary Research 66:599-605.

Gunja NJ, and Athanasiou KA. 2010. Additive and synergistic effects of bFGF and hypoxia on leporine meniscus cell-seeded PLLA scaffolds. J Tissue Eng Regen Med 4:115-122.

Gurdon JB, Lemaire P, and Kato K. 1993. Community effects and related phenomena in development. Cell 75:831-834.

Hee CK, Jonikas MA, and Nicoll SB. 2006. Influence of three-dimensional scaffold on the expression of osteogenic differentiation markers by human dermal fibroblasts. Biomaterials 27:875-884.

Hu $\mathrm{J}$ and Athanasiou K. 2005. Low density cultures of bovine chondrocytes: effects of scaffold material and culture system. Biomaterials 26:2001-2012.

Huey DJ, and Athanasiou KA. 2011. Maturational growth of self-assembled, functional menisci as a result of TGF-beta1 and enzymatic chondroitinase-ABC stimulation. Biomaterials 32:2052-2058.

Imler SM, Doshi AN, and Levenston ME. 2004. Combined effects of growth factors and static mechanical compression on meniscus explant biosynthesis. Osteoarthritis Cartilage 12:736-744.

Ionescu LC, and Mauck RL. 2013. Porosity and cell preseeding influence electrospun scaffold maturation and meniscus integration in vitro. Tissue Eng Part A 19:538-547.

Kambic HE, and McDevitt CA. 2005. Spatial organization of types I and II collagen in the canine meniscus. $J$ Orthop Res 23:142-149.

Kang SW, Son SM, Lee JS, Lee ES, Lee KY, Park SG, Park JH, and Kim BS. 2006. Regeneration of whole meniscus using meniscal cells and polymer scaffolds in a rabbit total meniscectomy model. $J$ Biomed Mater Res $A$ 77:659-671. 
488

489

490

491

492

493
Kim B, Putnam A, Kulik J. 1998. Optimizing seeding and culture methods to engineer smooth muscle tissue on biodegradable polymer matricies. Biotechnology and Bioengineering 57:46-54.

Kobayashi K, Fujimoto E, Deie M, Sumen Y, Ikuta Y, and Ochi M. 2004. Regional differences in the healing potential of the meniscus-an organ culture model to eliminate the influence of microvasculature and the synovium. Knee 11:271-278. 
Kobuna Y, Shirakura K, and Niijima M. 1995. Meniscal repair using a flap of synovium. An experimental study in the dog. Am J Knee Surg 8:52-55.

Lavik E, Teng YD, Snyder E, and Langer R. 2002. Seeding neural stem cells on scaffolds of PGA, PLA, and their copolymers. Methods Mol Biol 198:89-97.

Levick JR, Price FM, Mason FM. 1996. Synovial matrix-synovial fluild systems of joints. In: WD Comper (ed): Extracellular Matrix. Amsterdam: Harwood Academic Publishers, 235-252.

Loukas CG, Wilson GD, Vojnovic B, and Linney A. 2003. An image analysis-based approach for automated counting of cancer cell nuclei in tissue sections. Cytometry $A$ 55:30-42.

Mahmoudifar N, Doran P. 2005. Tissue engineering human cartilage in bioreactors using single and composite cell seeded scaffolds. Biotechnology and Bioengineering 91:338355.

Mahmoudifar N, Sikavistas V, Bancroif G, and Mikko A. 2002. Formation of three dimensional cell/ polymer constructs for bone tissue engineering in a spinner flask and a rotating wall vessel bioreactor. Journal of Bimedical Material Research 62:136148.

Mauck RL, Seyhan SL, Ateshian GA, and Hung CT. 2002. Influence of seeding density and dynamic deformational loading on the developing structure/function relationships of chondrocyte-seeded agarose hydrogels. Ann Biomed Eng 30:1046-1056.

Moran J, Pazzano B, and Bonassar L. 2003. Characterization of polylactic acid polyglycolic acid composites for cartilage tissue engineering. Tissue Eng 9:63-70.

Mueller SM, Shortkroff S, Schneider TO, Breinan HA, Yannas IV, and Spector M. 1999. Meniscus cells seeded in type I and type II collagen-GAG matrices in vitro. Biomaterials 20:701-709.

Narita A, Takahara M, Ogino T, Fukushima S, Kimura Y, and Tabata Y. 2009. Effect of gelatin hydrogel incorporating fibroblast growth factor 2 on human meniscal cells in an organ culture model. Knee 16:285-289.

Nishimura K, Solchaga LA, Caplan AI, Yoo JU, Goldberg VM, and Johnstone B. 1999. Chondroprogenitor cells of synovial tissue. Arthritis Rheum 42:2631-2637.

Ochi M, Mochizuki Y, Deie M, and Ikuta Y. 1996. Augmented meniscal healing with free synovial autografts: an organ culture model. Arch Orthop Trauma Surg 115:123-126.

Pazzano D, Davisson T, Seidel J, Pei M, GrayM. 2004. Long term culture of tissue engineered cartilage in a perfused chamber with mechanical stimulation. Biorheology 41:445-458. 
Pazzano D, Mercier K, Moran J. 2000. Comparison of chondrogenensis in static and perfused bioreactor culture. Biotechnology Progress 16:893-896.

Pei M, He F, and Vunjak-Novakovic G. 2008. Synovium-derived stem cell-based chondrogenesis. Differentiation 76:1044-1056.

Pei, M., He, F., Kish, V.L., Vunjak-Novakovic, G. 2008. Engineering of functional cartilage tissue using stem cells from synovial lining: a preliminary study. Clinical Orthopedics and Related Research 466, 1880-1889.

Peroni JF, and Stick JA. 2002. Evaluation of a cranial arthroscopic approach to the stifle joint for the treatment of femorotibial joint disease in horses: 23 cases (1998-1999). $J$ Am Vet Med Assoc 220:1046-1052.

Reddy GK, and Enwemeka CS. 1996. A simplified method for the analysis of hydroxyproline in biological tissues. Clin Biochem 29:225-229.

Rodeo SA, Seneviratne A, Suzuki K, Felker K, Wickiewicz TL, and Warren RF. 2000. Histological analysis of human meniscal allografts. A preliminary report. $J$ Bone Joint Surg Am 82-A:1071-1082.

Sakimura K, Matsumoto T, Miyamoto C, Osaki M, and Shindo H. 2006. Effects of insulinlike growth factor I on transforming growth factor beta1 induced chondrogenesis of synovium-derived mesenchymal stem cells cultured in a polyglycolic acid scaffold. Cells Tissues Organs 183:55-61.

Sha'ban M, Kim SH, Idrus RB, and Khang G. 2008. Fibrin and poly(lactic-co-glycolic acid) hybrid scaffold promotes early chondrogenesis of articular chondrocytes: an in vitro study. J Orthop Surg 3:17.

Sherwood JK, Riley SL, Palazzolo R, Brown SC, Monkhouse DC, Coates M, Griffith LG, Landeen LK, and Ratcliffe A. 2002. A three-dimensional osteochondral composite scaffold for articular cartilage repair. Biomaterials 23:4739-4751.

Shirakura K, Niijima M, Kobuna Y, and Kizuki S. 1997. Free synovium promotes meniscal healing. Synovium, muscle and synthetic mesh compared in dogs. Acta Orthop Scand 68:51-54.

Smith R, Dunlon B, Gupta, E. 1995. Effects of fluid induced shear on articular chondrocyte morphology and metabolism in vitro. Journal of Orthopaedic Research 13:824.

Stading M, and R L. 1999. Mechanical shear properties of cell-polymer cartilage constructs. Tissue Eng 5:241-250.

Strober W. 2001. Trypan blue exclusion test of cell viability. Curr Protoc Immunol Appendix 3:Appendix 3B.

Tan, Y., Zhang, Y., and Pei, M. 2010. Meniscus reconstruction through coculturing 
564

565

566

567

568

569

570

571

572

573

574

575

576

577

578

579 meniscus cells with synovium-derived stem cells on small intestine submucosa-a pilot study to engineer meniscus tissue constructs. Tissue Eng Part A 16, 67-79.

Valiyaveettil M, Mort JS, and McDevitt CA. 2005. The concentration, gene expression, and spatial distribution of aggrecan in canine articular cartilage, meniscus, and anterior and posterior cruciate ligaments: a new molecular distinction between hyaline cartilage and fibrocartilage in the knee joint. Connect Tissue Res 46:83-91.

Vunjak-Novakovic G, Obradovic B, Martin I, Bursac PM, Langer R, and Freed LE. 1998. Dynamic cell seeding of polymer scaffolds for cartilage tissue engineering. Biotechnol Prog 14:193-202.

Walmsley JP. 1995. Vertical tears of the cranial horn of the meniscus and its cranial ligament in the equine femorotibial joint: 7 cases and their treatment by arthroscopic surgery. Equine Vet $J$ 27:20-25.

Walmsley JR, Phillips TJ, and Townsend HG. 2003. Meniscal tears in horses: an evaluation of clinical signs and arthroscopic treatment of 80 cases. Equine Vet $J$ 35:402-406.

Wu F, Dunkelman N, and Peterson A. 1999. Bioreactor development for tissue engineered cartilage. Annals of the New York Academy of Science 875:405-411. 
581 Figure 1. Rotating wall bioreactor flask $(110 \mathrm{~mL})$ containing media and PGA scaffolds seeded 582 with equine fibroblast-like synoviocytes $(\mathbf{A})$. Flasks loaded on the rotating base apparatus; flasks 583 rotate around their longitudinal axis $(\mathbf{B})$.

584 Figure 2. Static culture of equine fibroblast- like synoviocytes on PGA scaffolds in a 24 well 585 tissue culture plate, with each well containing $2 \mathrm{~mL}$ of supplemented DMEM.

586

587

588

589

590

591

592

593

594

595

596

597

598

599

600

601

602

603

604

605

606

607

608

609

610

611

612

613

614

615

616

617

Figure 3. Method for viewing all scaffolds to standardize cell counts and determine regional cell count differences between the scaffold center and periphery. Cells were counted at the periphery and central regions (dark dotted circles) of each scaffold (cross- hatched circle) using digital image analysis; peripheral cell counts (light dotted circles) were obtained at the 2o'clock, 6o'clock and 19o'clock positions. Circles represent a low power (10X objective) field of view.

Figure 4. Scanning electron microscopy of a 2\% PLLA coated PGA scaffold (A) and a 4\% PLLA coated scaffold $(\mathbf{B})$ prior to cell seeding; bar $=100 \mu \mathrm{m}$.

Figure 5. Rotating wall bioreactor flask containing 2\% PLLA coated PGA scaffolds, strung on suture to ensure equal submersion and positioning in the rotating flask.

Figure 6. Micrographs of scaffolds seeded with equine fibroblast-like synoviocytes; Hematoxylin and Eosin staining, 10x objective magnification; bar $=100 \mu \mathrm{m}$. A) PGA scaffold cultured in a static environment; B) PGA scaffold cultured in a dynamic environment (rotating bioreactor); C) OPLA scaffold cultured in a dynamic environment (rotating bioreactor); D) OPLA scaffold cultured in a static environment. Note the intact PGA fibers (open arrow) and the cells located in clumps in the pores of the OPLA scaffold (closed arrows).

Figure 7. Mean \pm Standard Error of the Mean (SEM) of dsDNA content of PGA scaffolds coated in 2\% PLLA and 4\% PLLA, seeded dynamically and cultured in a rotating bioreactor for 14 days and 21 days. A bar and (*) indicates a significant difference between two treatment $\operatorname{groups}(\mathrm{P}<0.05)$.

Figure 8. Photomicrographs of 2\% PLLA coated PGA constructs harvested on day 10, under standard light (column A) and under laser confocal microscopy (column B), using the calcein AM-ethidium homodimer live-dead assay. Images represent scaffold transverse cross sections (row $\mathbf{T}$ ) and scaffold surface coronal sections (row $\mathbf{C}$ ). Green stained cells are alive, red stained cells are dead. 10x objective magnification; bar $=100 \mu \mathrm{m}$.

Figure 9. Photomicrographs of 2\% PLLA coated PGA constructs harvested on day 21, under standard light (column A) and under laser confocal microscopy (column B), using the calcein AM-ethidium homodimer live-dead assay. Images represent scaffold transverse cross sections (row $\mathbf{T}$ ) and scaffold surface coronal sections (row $\mathbf{C}$ ). Green stained cells are alive, red stained cells are dead. Note the spurious red staining of scaffold PGA fibers. 10x objective magnification; bar $=100 \mu \mathrm{m}$. 
618 AM-ethidium homodimer live-dead assay. Images represent scaffold transverse cross sections

619 (row T) and scaffold surface coronal sections (row C). Green stained cells are alive, red stained 620 cells are dead. Note the spurious red staining of PGA fibers. 10x objective magnification; bar = $621100 \mu \mathrm{m}$.

622 Figure 11. Photomicrographs of 4\% PLLA coated PGA constructs harvested on day 21, under 623 standard light (column A) and under laser confocal microscopy (column B), using the calcein 624 AM-ethidium homodimer live-dead assay. Images represent scaffold transverse cross sections 625 (row $\mathbf{T}$ ) and scaffold surface coronal sections (row $\mathbf{C}$ ). Green stained cells are alive, red stained 626 cells are dead. Note the spurious red staining of PGA fibers.10x objective magnification; bar = $627100 \mu \mathrm{m}$.

628 Figure 12. Photomicrographs of 2\% PLLA coated PGA scaffolds harvested on day 10 (row 1) 629 and day 21 (row 2), and 4\% PLLA coated PGA scaffolds harvested on day 10 (row 3) and day 21 630 (row 4), $\mathrm{H}+\mathrm{E}$ staining. Column $\mathbf{A}$ represents images of the center of the construct and column $\mathbf{B}$ 631 represents images taken of the scaffold periphery. Note that the cells have grown in dense 632 clusters; 10x objective magnification; bar $=100 \mu \mathrm{m}$. 


\section{Figure 1}

Dynamic culture: rotating bioreactor apparatus.

Rotating wall bioreactor flask $(110 \mathrm{~mL})$ containing media and PGA scaffolds seeded with equine fibroblast-like synoviocytes (A). Flasks loaded on the rotating base apparatus; flasks rotate around their longitudinal axis $(B)$.
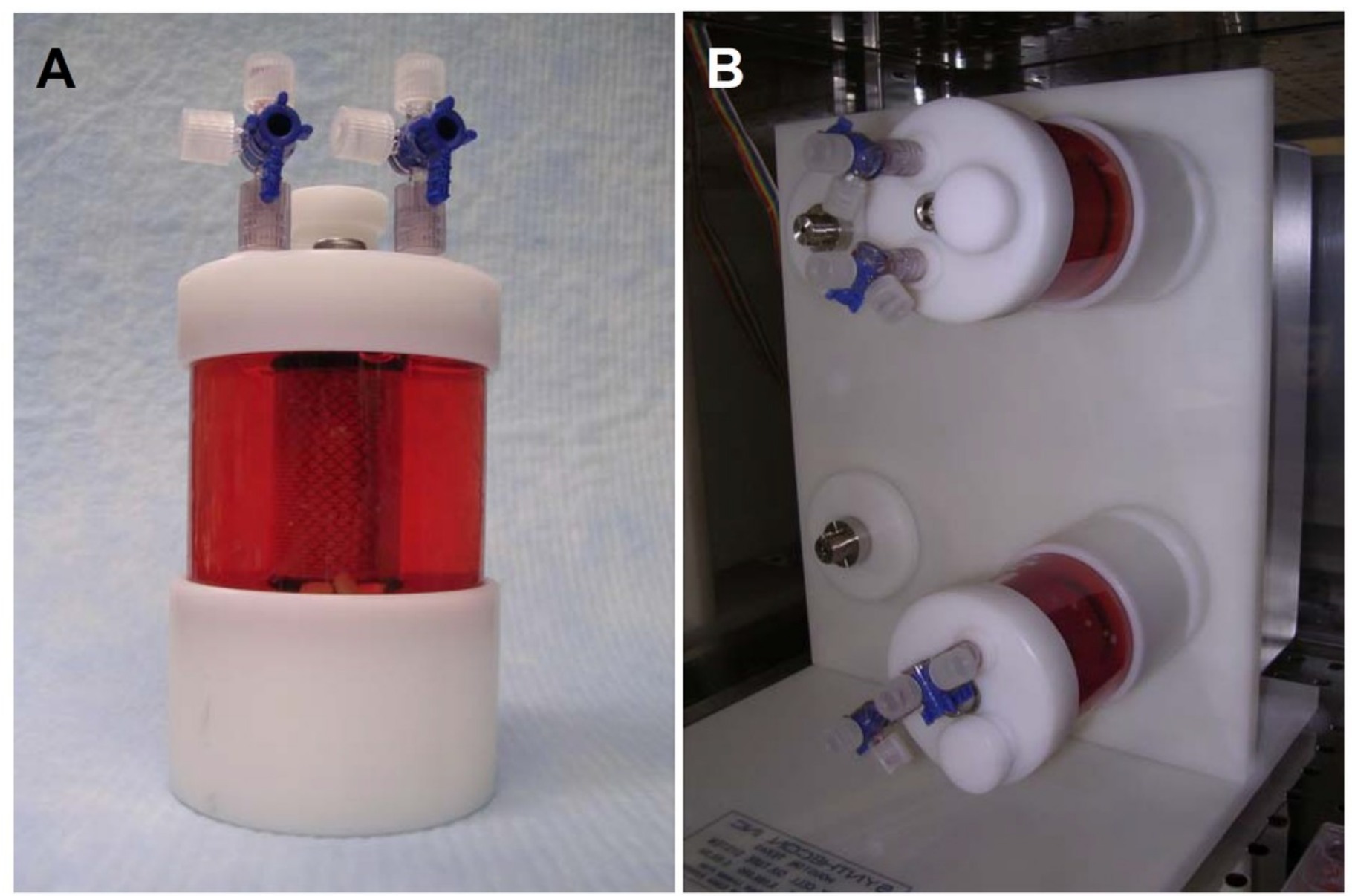


\section{Figure 2}

Static culture.

Static culture of equine fibroblast- like synoviocytes on PGA scaffolds in a 24 well tissue culture plate, with each well containing $2 \mathrm{~mL}$ of supplemented DMEM.

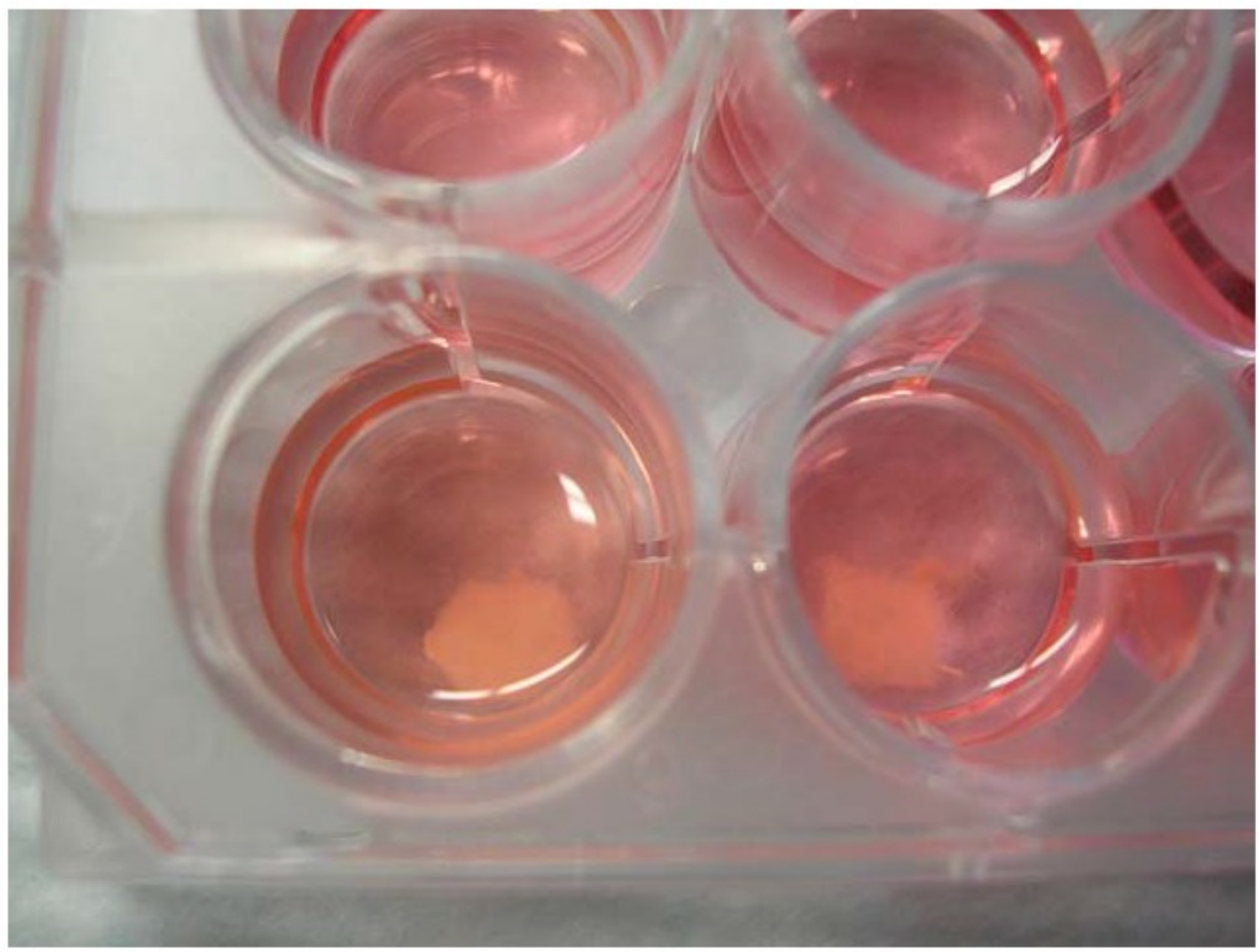




\section{Figure 3}

Histologic cell counting method.

Method for viewing all scaffolds to standardize cell counts and determine regional cell count differences between the scaffold center and periphery. Cells were counted at the periphery and central regions (dark dotted circles) of each scaffold (cross- hatched circle) using digital image analysis; peripheral cell counts (light dotted circles) were obtained at the 2o'clock, $60^{\prime}$ clock and 19o'clock positions. Circles represent a low power (10X objective) field of view.

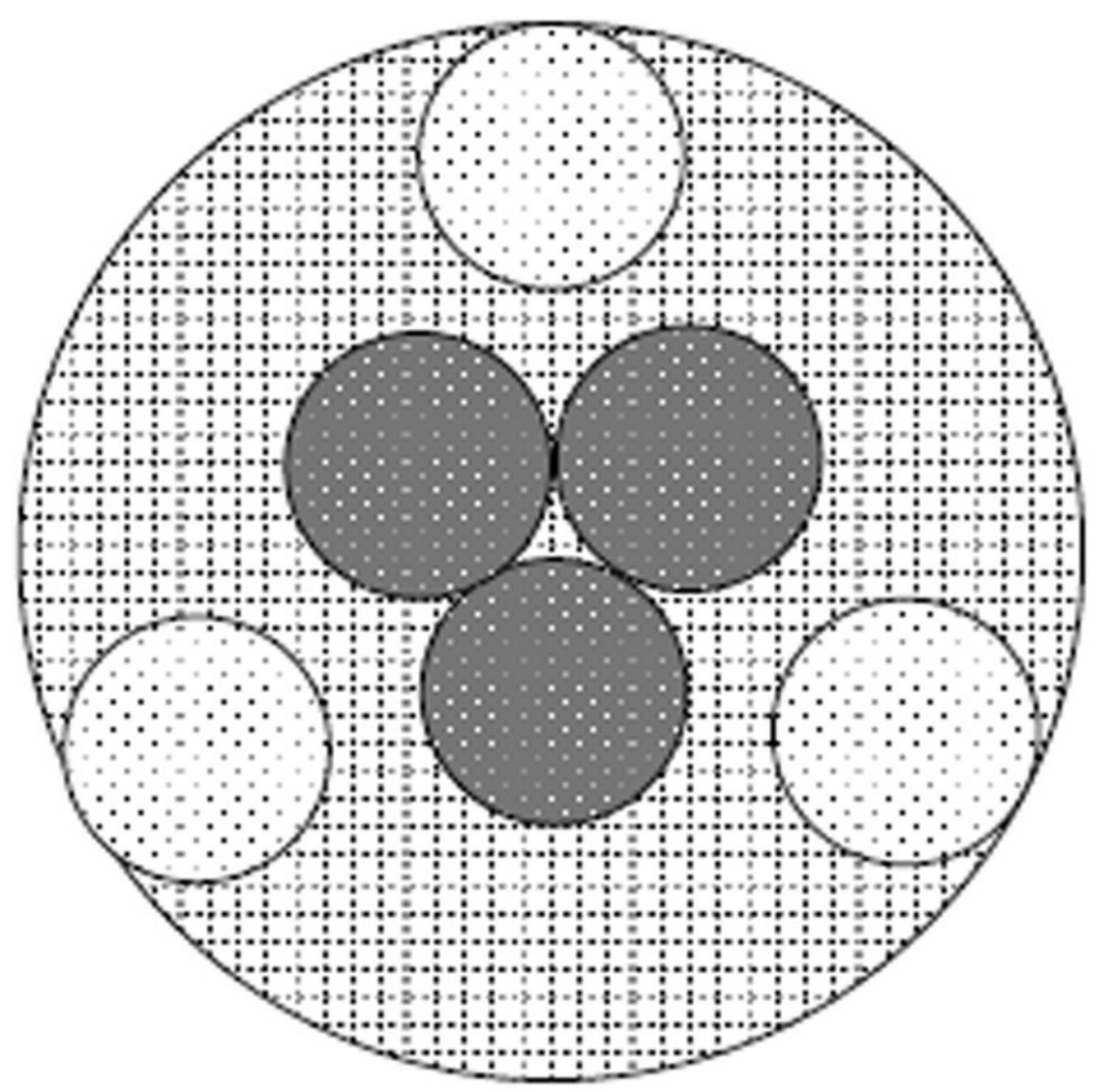




\section{Figure 4}

PLLA coated scaffolds.

Scanning electron microscopy of a $2 \%$ PLLA coated PGA scaffold (A) and a 4\% PLLA coated scaffold (B) prior to cell seeding; bar $=100 \mu \mathrm{m}$.
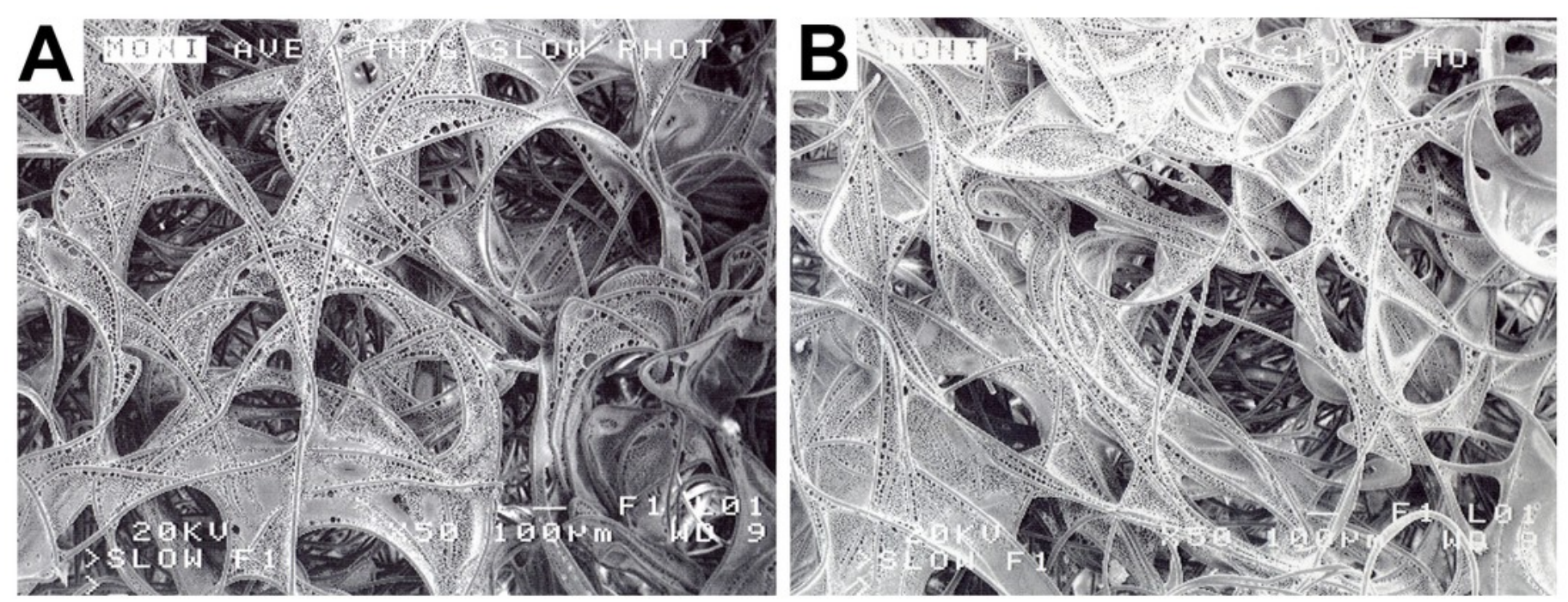


\section{Figure 5}

Positioning of PLLA coated scaffolds in the rotating bioreactor.

Rotating wall bioreactor flask containing 2\% PLLA coated PGA scaffolds, strung on suture to ensure equal submersion and positioning in the rotating flask. 


\section{Figure 6}

Histologic cell distribution on PGA and OPLA scaffolds.

Micrographs of scaffolds seeded with equine fibroblast-like synoviocytes; Hematoxylin and Eosin staining, 10x objective magnification; bar $=100 \mu \mathrm{m}$. A) PGA scaffold cultured in a static environment; B) PGA scaffold cultured in a dynamic environment (rotating bioreactor); C) OPLA scaffold cultured in a dynamic environment (rotating bioreactor); D) OPLA scaffold cultured in a static environment. Note the intact PGA fibers (open arrow) and the cells located in clumps in the pores of the OPLA scaffold (closed arrows). 

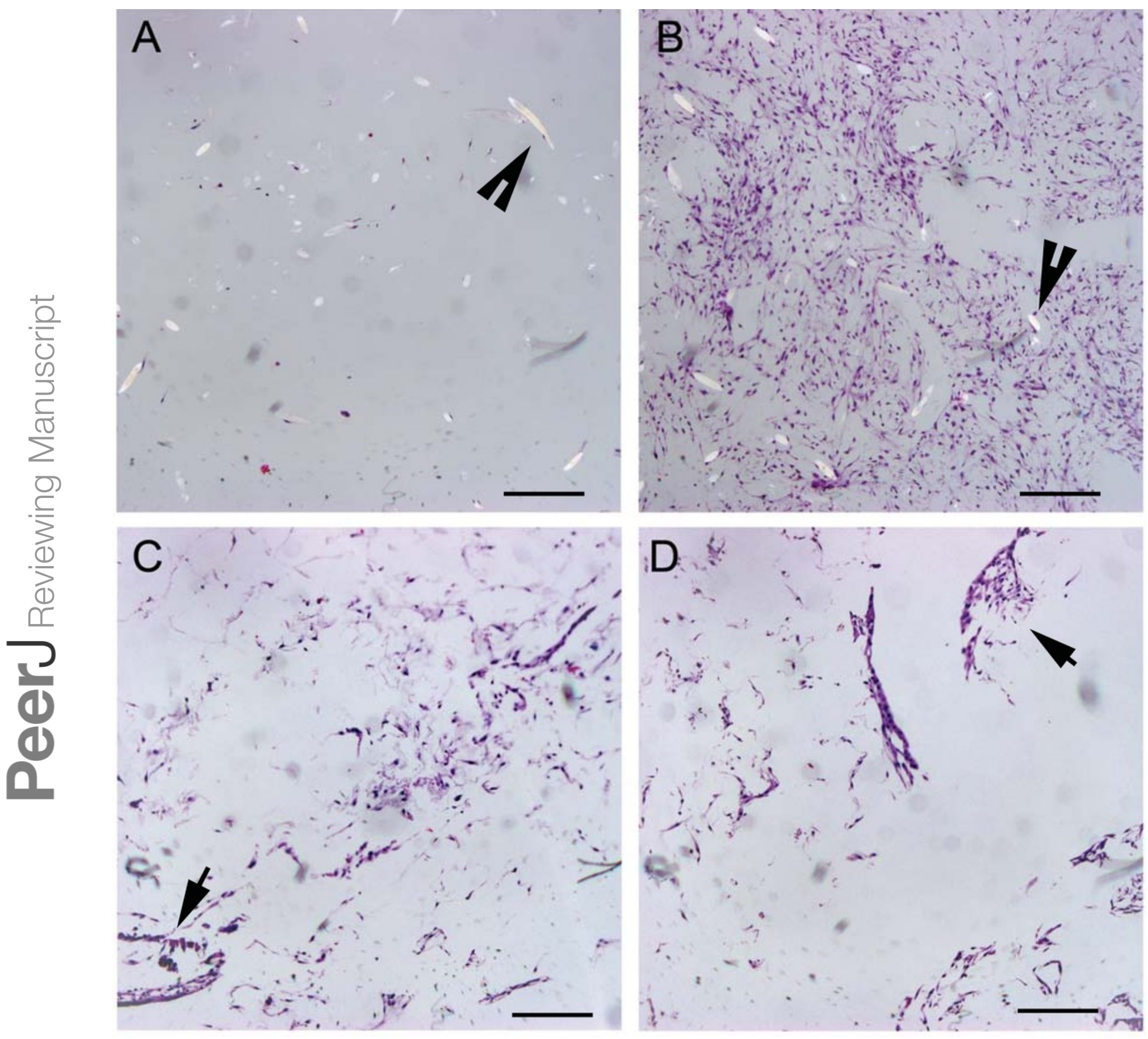


\section{Figure 7}

Double stranded DNA content of PLLA coated scaffolds.

Mean \pm Standard Error of the Mean (SEM) of dsDNA content of PGA scaffolds coated in $2 \%$ PLLA and 4\% PLLA, seeded dynamically and cultured in a rotating bioreactor for 14 days and 21 days. A bar and $\left(^{*}\right)$ indicates a significant difference between two treatment groups $(P<0.05)$. 


\section{Scaffold Cellularity as Measured by dsDNA content}

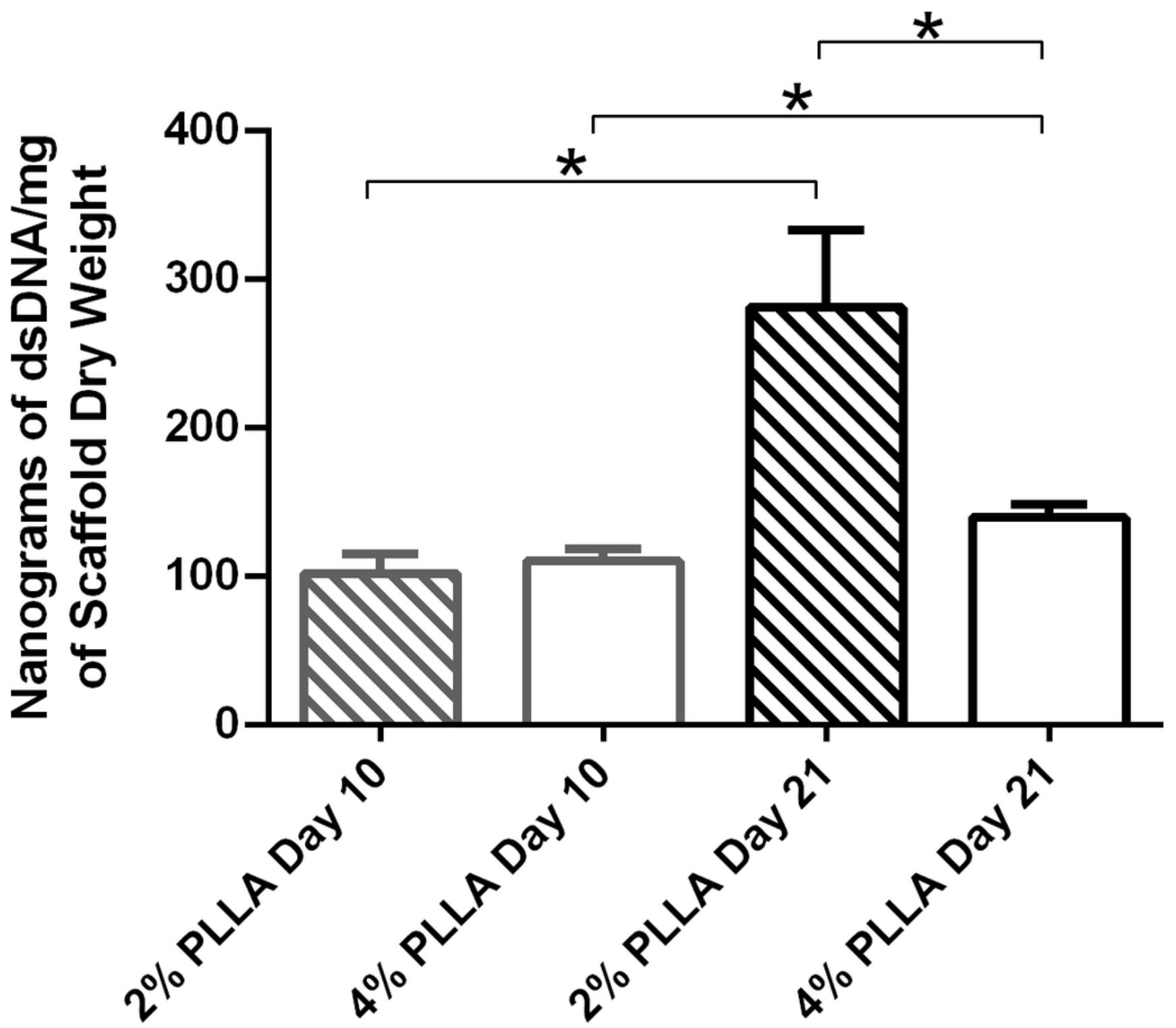

Treatment Group 


\section{Figure 8}

Cell viability: 2\% PLLA scaffolds

Photomicrographs of 2\% PLLA coated PGA constructs harvested on day 10 , under standard light (column A) and under laser confocal microscopy (column B), using the calcein AMethidium homodimer live-dead assay. Images represent scaffold transverse cross sections (row $\mathbf{T}$ ) and scaffold surface coronal sections (row $\mathbf{C}$ ). Green stained cells are alive, red stained cells are dead. $10 x$ objective magnification; bar $=100 \mu \mathrm{m}$. 
A B

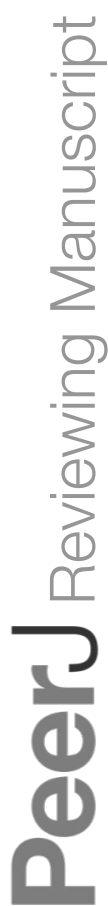

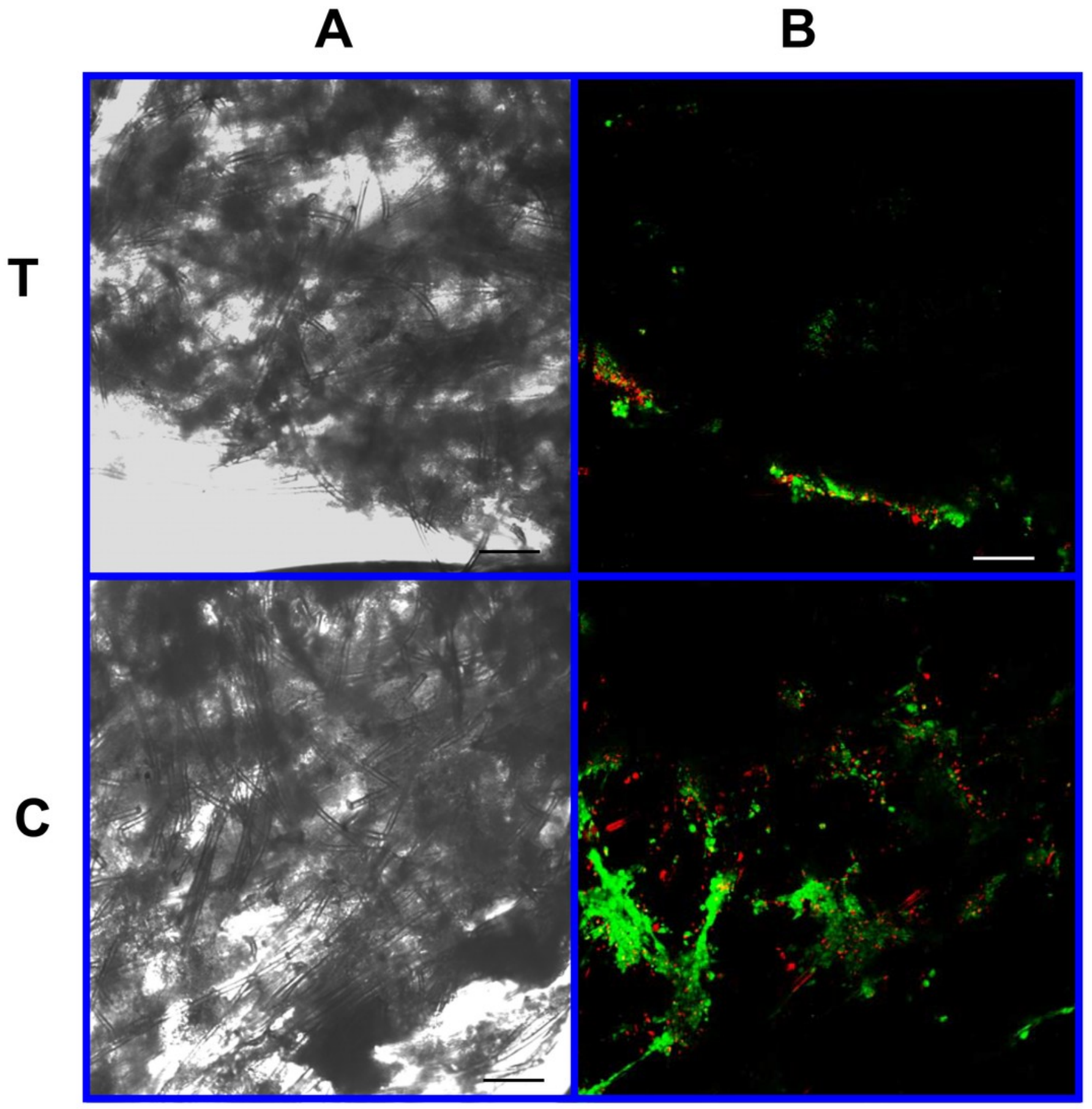




\section{Figure 9}

Cell viability: 2\% PLLA scaffolds

Photomicrographs of 2\% PLLA coated PGA constructs harvested on day 21, under standard light (column A) and under laser confocal microscopy (column B), using the calcein AMethidium homodimer live-dead assay. Images represent scaffold transverse cross sections (row $\mathbf{T}$ ) and scaffold surface coronal sections (row $\mathbf{C}$ ). Green stained cells are alive, red stained cells are dead. Note the spurious red staining of scaffold PGA fibers. 10x objective magnification; bar $=100 \mu \mathrm{m}$. 


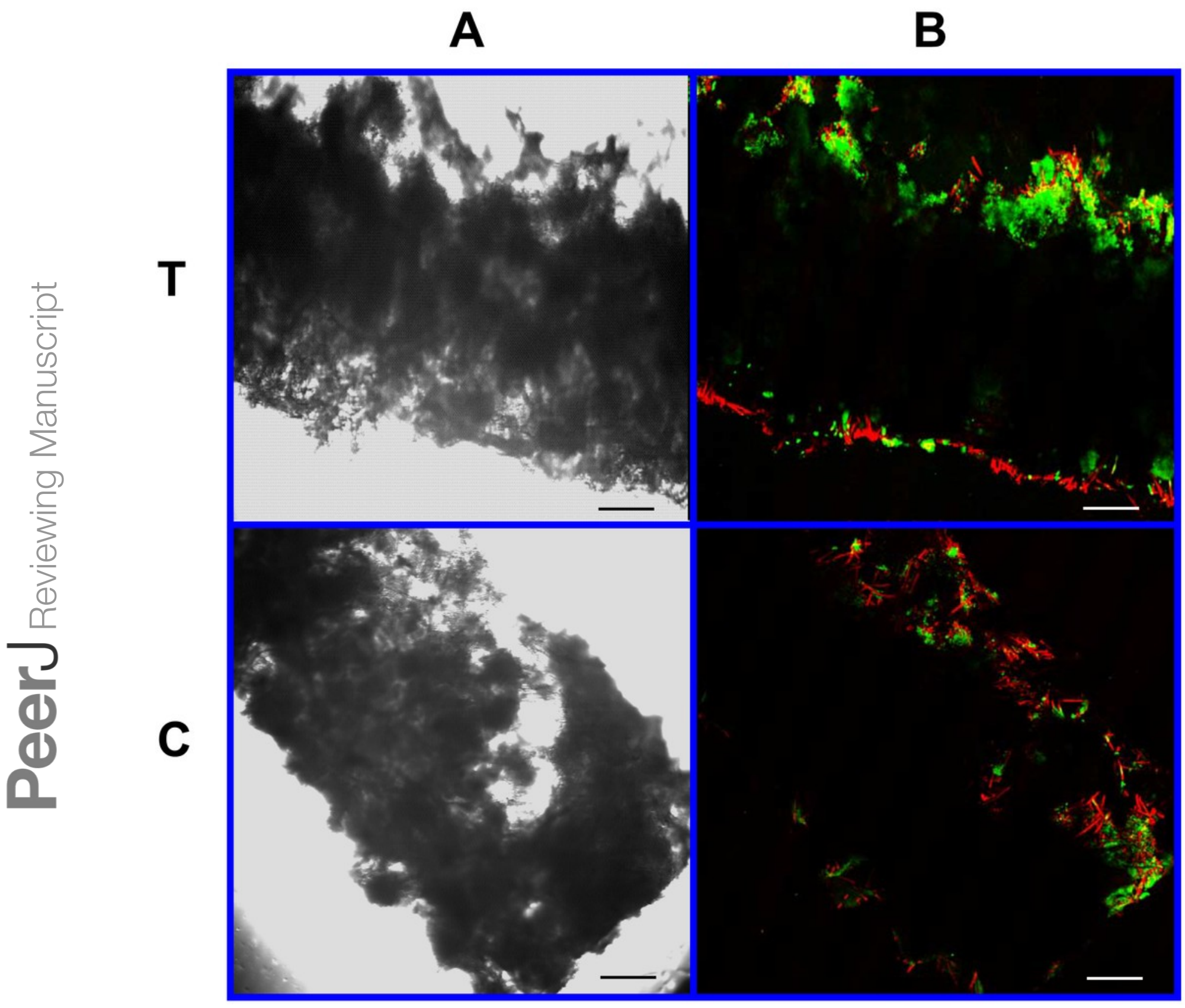




\section{Figure 10}

Cell viability assay: 4\% PLLA scaffolds

Photomicrographs of 4\% PLLA coated PGA constructs harvested on day 10 , under standard light (column A) and under laser confocal microscopy (column B), using the calcein AMethidium homodimer live-dead assay. Images represent scaffold transverse cross sections (row $\mathbf{T}$ ) and scaffold surface coronal sections (row $\mathbf{C}$ ). Green stained cells are alive, red stained cells are dead. Note the spurious red staining of PGA fibers. 10x objective magnification; bar $=100 \mu \mathrm{m}$. 


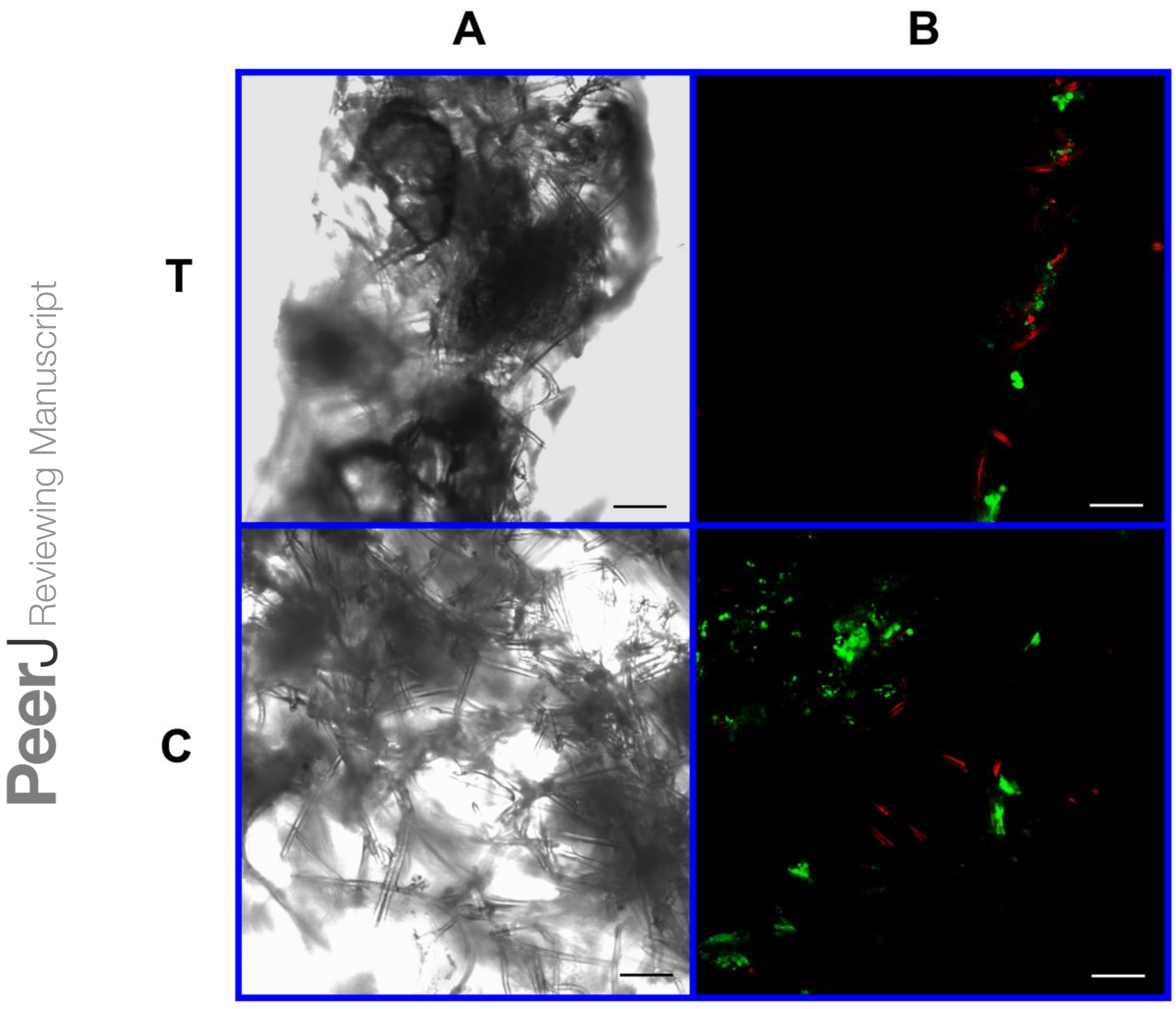




\section{Figure 11}

Cell viability: 4\% PLLA scaffolds

Photomicrographs of 4\% PLLA coated PGA constructs harvested on day 21, under standard light (column A) and under laser confocal microscopy (column B), using the calcein AMethidium homodimer live-dead assay. Images represent scaffold transverse cross sections (row T) and scaffold surface coronal sections (row $\mathbf{C}$ ). Green stained cells are alive, red stained cells are dead. Note the spurious red staining of PGA fibers.10x objective magnification; bar $=100 \mu \mathrm{m}$. 


\section{Figure 12}

Distribution of cells on $2 \%$ and $4 \%$ PLLA coated PGA scaffolds

Figure 12. Photomicrographs of $2 \%$ PLLA coated PGA scaffolds harvested on day 10 (row 1) and day 21 (row 2), and 4\% PLLA coated PGA scaffolds harvested on day 10 (row 3) and day 21 (row 4), H+E staining. Column A represents images of the center of the construct and column B represents images taken of the scaffold periphery. Note that the cells have grown in dense clusters; $10 x$ objective magnification; bar $=100 \mu \mathrm{m}$. 


\section{Table 1 (on next page)}

The effect of seeding and cell culture biomechanical environment and the effect of scaffold type on scaffold cellularity. 


\begin{tabular}{|l|l|l|l|}
\hline & \multicolumn{2}{|l|}{$\begin{array}{l}\text { Cell Count } \\
\text { (Mean number of cells per 10x } \\
\text { objective field } \pm \text { SD) }\end{array}$} & $\begin{array}{l}\text { Effect of biomechanical } \\
\text { environment (dynamic } \\
\text { vs static culture) }\end{array}$ \\
\hline Scaffold type: & Biomechanical environment: & \\
\hline & $\begin{array}{l}\text { Dynamic } \\
\text { culture }\end{array}$ & Static culture & \\
\hline PGA & $\begin{array}{l}1128 \pm 575 \\
\text { cells }\end{array}$ & $54 \pm 34$ cells & $\mathrm{P}<0.001$ \\
\hline OPLA & $375 \pm 118$ cells & $301 \pm 65$ cells & $\mathrm{P}=0.028$ \\
\hline & & & \\
\hline $\begin{array}{l}\text { Effect of scaffold type } \\
\text { (PGA vs OPLA) }\end{array}$ & $\mathrm{P}=0.017$ & $\mathrm{P}=0.0217$ & \\
\hline
\end{tabular}




\section{Table 2 (on next page)}

Peripheral and central cell count (Mean number of cells per 10x objective field \pm SD). 


\begin{tabular}{|l|l|l|l|}
\hline Scaffold & Peripheral cell count & Central cell count & P- value \\
\hline PGA-D & $1433 \pm 487$ & $724 \pm 314$ & $\mathrm{P}<0.001$ \\
\hline PGA-S & $80 \pm 28$ & $28 \pm 11$ & $\mathrm{P}<0.001$ \\
\hline OPLA-D & $476 \pm 90$ & $295 \pm 55$ & $\mathrm{P}<0.001$ \\
\hline
\end{tabular}

